\title{
Similarity Solution of Heat and Mass Transfer for Natural Convection over a Moving Vertical Plate with Internal Heat Generation and a Convective Boundary Condition in the Presence of Thermal Radiation, Viscous Dissipation, and Chemical Reaction
}

\author{
S. Mohammed Ibrahim ${ }^{1}$ and N. Bhashar Reddy ${ }^{2}$ \\ ${ }^{1}$ Department of Mathematics, Priyadarshini College of Engineering and Technology, Nellore 524004, India \\ ${ }^{2}$ Department of Mathematics, Sri Venkateswara University, Tirupat 517501, India \\ Correspondence should be addressed to S. Mohammed Ibrahim; ibrahimsvu@gmail.com
}

Received 14 April 2013; Accepted 7 July 2013

Academic Editors: R. R. Burnette, T. M. Inerbaev, and P. Trens

Copyright (C) 2013 S. M. Ibrahim and N. Bhashar Reddy. This is an open access article distributed under the Creative Commons Attribution License, which permits unrestricted use, distribution, and reproduction in any medium, provided the original work is properly cited.

\begin{abstract}
Steady laminar natural convection flow over a semi-infinite moving vertical plate with internal heat generation and convective surface boundary condition in the presence of thermal radiation, viscous dissipation, and chemical reaction is examined in this paper. In the analysis, we assumed that the left surface of the plate is in contact with a hot fluid while the cold fluid on the right surface of the plate contains a heat source that decays exponentially with the classical similarity variable. We utilized similarity variable to transform the governing nonlinear partial differential equations into a system of ordinary differential equations, which are solved numerically by applying shooting iteration technique along fourth-order Runge-Kutta method. The effects of the local Biot number, Prandtl number, buoyancy forces, the internal heat generation, the thermal radiation, Eckert number, viscous dissipation, and chemical reaction on the velocity, temperature, and concentration profiles are illustrated and interpreted in physical terms. A comparison with previously published results on the similar special cases showed an excellent agreement. Finally, numerical values of physical quantities, such as the local skin-friction coefficient, the local Nusselt number, and the local Sherwood number, are presented in tabular form.
\end{abstract}

\section{Introduction}

Convective flows with simultaneous heat and mass transfer under the influence of the chemical reaction arise in many transport processes both naturally and artificially in many branches of science and engineering applications. This phenomenon plays an important role in the chemical industry, power and cooling industry for drying, chemical vapour deposition on surfaces, cooling of nuclear reactors, and petroleum industries.

Natural convection flow occurs frequently in nature. It occurs due to temperature differences, as well as due to concentration differences or the combination of these two; for example, in atmospheric flows, there exist differences in water concentration, and hence the flow is influenced by such concentration difference.

Changes in fluid density gradients may be caused by nonreversible chemical reaction in the system as well as by the differences in the molecular weight between values of the reactants and the products. Chemical reactions can be modeled as either homogenous or heterogeneous processes. This depends on whether they occur at an interface or as a single phase value reaction. A homogeneous reaction is one that occurs uniformly throughout a given phase. On the other hand, a heterogeneous reaction takes place in a restricted area or within the boundary of a phase. In most cases of chemical reaction, the reaction rate depends on the concentration of the species itself. A reaction is said to be of 
first order if the rate of reaction is directly proportional to the concentration itself (Cussler [1]). For example, the formation of smog is a first-order homogeneous reaction. Consider the emission of nitrogen dioxide from automobiles and other smog stacks. This nitrogen dioxide reacts chemically in the atmosphere with unburned hydrocarbons (aided by sunlight) and produces peroxyacetylnitrate, which forms an envelope which is turned photochemical smog. The study of heat and mass transfer with chemical reaction is of great practical importance in many branches of science and engineering. Das et al. [2] studied the effects of mass transfer flow past an impulsively started infinite vertical plate with constant heat flux and chemical reaction. Anjalidevi and Kandasamy [3] found the effects of chemical reaction, heat, and mass transfer on laminar flow along a semi-infinite horizontal plate. More recently, intensive studies have been carried out to investigate the effects of chemical reaction and different flow types (see Seddeek et al. [4]. Salem and Abd El-Aziz [5], Mohamed [6], and Ibrahim et al. [7]).

The study of heat generation or absorption in moving fluids is important in problems dealing with chemical reactions and those concerned with dissociating fluids. Heat generation effects may alter the temperature distribution, and these in turn can affect the particle deposition rate in nuclear reactors, electronic chips, and semiconductor's wafers. Although exact modeling of internal heat generation or absorption is quite difficult, some simple mathematical models can be used to express its general behavior for most physical situations. Heat generation or absorption can be assumed to be constant, space dependent, or temperature dependent. Crepeau and Clarksean [8] have used a space-dependent exponentially decaying heat generation or absorption in their study on flow and heat transfer from vertical plate. Several interesting computational studies of reactive MHD boundary layer flows with heat and mass transfer in the presence of heat generation or absorption have appeared in recent years (see Patil and Kulkarni [9], Salem and Abd El-Aziz [5], Mohamed [6], and Mahdy [10]).

Convective heat transfer studies are very important in processes involving high temperatures, such as gas turbines, nuclear plants, and thermal energy storage. Ishak [11] examined the similarity solutions for flow and heat transfer over a permeable surface with convective boundary condition. Moreover, Aziz [12] studied a similarity solution for laminar thermal boundary layer over a flat plate with a convective surface boundary condition and also studied hydrodynamic and thermal slip flow boundary layers over a flat plate with a constant heat flux boundary condition. Makinde and Olanrewaju [13] investigated the buoyancy effects on a thermal boundary layer over a vertical plate with a convective surface boundary condition. More recently, Makinde [14] studied similarity solution for natural convection from a moving vertical plate with internal heat generation and a convective boundary condition. Olanrewaju et al. [15] examined the effects of internal heat generation, thermal radiation, and buoyancy force on a boundary layer over a vertical plate with a convective surface boundary condition. Makinde and Olanrewaju [16] investigated the combined effects of internal heat generation and buoyancy force on boundary layer flow over a vertical plate with a convective surface boundary condition.

Viscous dissipation changes the temperature distributions by playing a role like an energy source, which leads to the affected heat transfer rates. The merit of the effect of viscous dissipation depends on whether the plate is being cooled or heated. Heat transfer analysis over porous surface is of much practical interest due to its abundant applications. To be more specific, heat-treated materials traveling between a feed roll and wind-up roll or materials manufactured by extrusion, glass-fiber and paper production, cooling of metallic sheets or electronic chips, and crystal growing, just to name a few. In these cases, the final product of desired characteristics depends on the rate of cooling in the process and the process of stretching. The work of Sonth et al. [17] deals with the effect of the viscous dissipation term along with temperature-dependent heat source/sink on momentum and heat and mass transfer in a viscoelastic fluid flow over an accelerating surface. Chen [18] examined the effect of combined heat and mass transfer on MHD-free convection from a vertical surface with ohmic heating and viscous dissipation. The effect of viscous dissipation and Joule heating on MHD-free convection flow past a semi-infinite vertical flat plate in the presence of the combined effect of Hall and nonslip currents for the case of power-law variation of the wall temperature is analyzed by Abo-Eldahab and El Aziz [19].

In many new engineering areas processes such as fossil fuel combustion energy processes, solar power technology, astrophysical flows, gas turbines, and the various propulsion devices for aircraft, missiles, satellites, and space vehicle reentry occur at high temperatures so knowledge of radiation heat transfer beside the convective heat transfer plays a very important role and hence its effect cannot be neglected. Also thermal radiation is of major importance in many processes in engineering areas which occur at a very high temperature for the design of many advanced energy conversion systems and pertinent equipment. The Rosseland approximation is used to describe the radiative heat flux in the energy equation. Pal and Mondal [20] investigate the unsteady twodimensional MHD non-Darcian mixed convection heat and mass transfer past a semi-infinite vertical permeable plate embedded in a porous medium by taking into account Soret and Dufour effects in the presence of suction or injection, thermal radiation, and first-order chemical reaction. Uwanta [21] studied the effects of chemical reaction and radiation on heat and mass transfer past a semi-infinite vertical porous plate with constant mass flux and dissipation. Olanrewaju et al. [22] found the effects of internal heat generation, thermal radiation, and buoyancy force on a boundary layer over a vertical plate with a convective surface boundary condition.

The objective of this paper was to explore the effects of thermal radiation, heat generation, viscous dissipation, and chemical reaction on the similarity solution for natural convection from a moving vertical plate under a convective boundary condition, which is an extension of Makinde [14] with the addition of thermal radiation, viscous dissipation, and chemical reaction parameter for more physical implications. Using a similarity approach, the governing 
equations are transformed into nonlinear ordinary equations and solved numerically using shooting iteration technique together with fourth-order Runge-Kutta integration scheme. The pertinent results are displayed graphically and discussed quantitatively.

\section{Mathematical Formulation}

We consider the steady laminar incompressible natural convection boundary layer flows over the right surface of a vertical flat plate moving with uniform velocity $U_{0}$ in contact with a quiescence cold fluid at temperature $T_{\infty}$ and concentration $C_{\infty}$. The cold fluid on the right surface of the plate generates heat internally at the volumetric rate $\dot{q}$. The left surface of the plate is heated by convection from a hot fluid at temperature $T_{f}$ which provides a heat transfer coefficient $h_{f}$ as shown in Figure 1. Under the Boussinesq for fluid density variation, the continuity, momentum, energy equation, and mass diffusion equations describing the flow can be written as

$$
\begin{gathered}
\frac{\partial u}{\partial x}+\frac{\partial v}{\partial y}=0 \\
u \frac{\partial u}{\partial x}+v \frac{\partial u}{\partial y}=v \frac{\partial^{2} u}{\partial y^{2}}+g \beta\left(T-T_{\infty}\right)+g \beta^{*}\left(C-C_{\infty}\right) \\
\rho C_{p}\left(u \frac{\partial u}{\partial x}+v \frac{\partial u}{\partial y}\right)=k \frac{\partial^{2} T}{\partial y^{2}}+\dot{q}-\frac{\partial q_{r}}{\partial y}+\mu\left(\frac{\partial u}{\partial y}\right)^{2} \\
u \frac{\partial C}{\partial x}+v \frac{\partial C}{\partial y}=D \frac{\partial^{2} C}{\partial y^{2}}-K_{r}^{\prime}\left(C-C_{\infty}\right)
\end{gathered}
$$

where $u$ and $v$ are the $x$ (along the plate) and $y$ (normal to the plate) components of the velocities, respectively, $T$ is the temperature, $C$ is the concentration, $\mu$ is the fluid viscosity, $v$ is the kinematics viscosity of the fluid, $k$ is the thermal conductivity of the fluid, $\beta$ is the thermal expansion coefficient, $\beta^{*}$ is concentration expansion coefficient, $\dot{q}$ is the internally generated heat at volumetric rate, $g$ is the gravitational acceleration, $q_{r}$ is the radiative heat flux, $D$ is the diffusion coefficient, and $K_{r}^{\prime}$ is the chemical reaction parameter.

The boundary conditions at the plate surface and for the cold fluid may be written as

$$
\begin{gathered}
u(x, 0)=U_{0}, \quad v(x, 0)=0, \\
-K \frac{\partial T}{\partial y}(x, 0)=h_{f}\left[T_{f}-T(x, 0)\right], \\
C_{f}(x, 0)=A x^{\lambda}+C_{\infty}, \\
u(x, \infty)=0, \quad T(x, \infty)=T_{\infty}, \quad C(x, \infty)=C_{\infty} .
\end{gathered}
$$

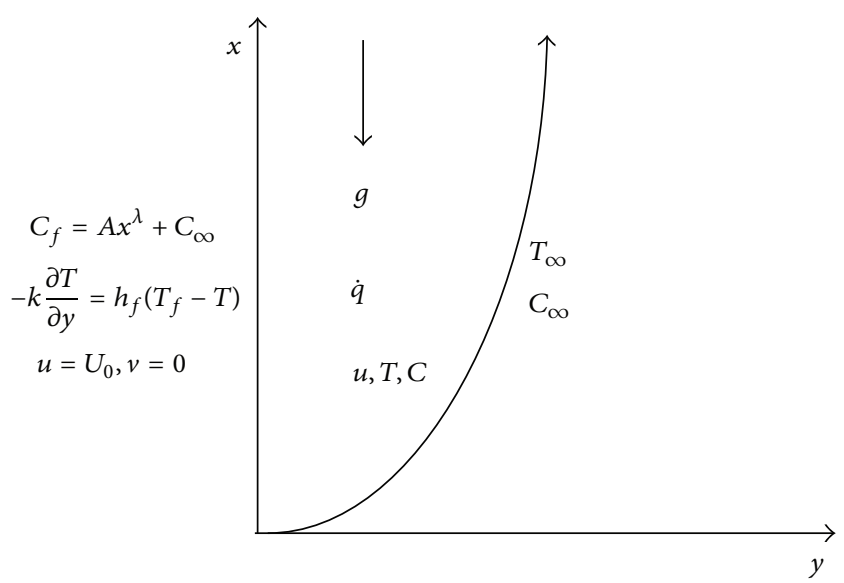

FIgURE 1: Flow configuration and coordinate system.

By using the Rosseland diffusion approximation Hossain et al. [23] and following Raptis [24] among other researchers the radiative heat flux, $q_{r}$ is given by

$$
q_{r}=-\frac{4 \sigma^{*}}{3 K_{s}} \frac{\partial T^{4}}{\partial y}
$$

where $\sigma^{*}$ and $K_{s}$ are the Stefan-Boltzmann constant and the mean absorption coefficient, respectively. Following Chamkha [25], we assume that the temperature differences within the flow are sufficiently small so that $T^{4}$ can be expressed as a linear function after using the Taylor series to expand $T^{4}$ about the free stream temperature $T_{\infty}$ and neglecting higher-order terms. This result is the following approximation:

$$
T^{4} \approx 4 T_{\infty}^{3} T-3 T_{\infty}^{4}
$$

Using (6) and (7) in (3), we obtain

$$
\frac{\partial q_{r}}{\partial y}=-\frac{16 \sigma^{*}}{3 K} \frac{\partial^{2} T^{4}}{\partial y^{2}}
$$

Introducing a similarity variable $\eta$ and a dimensionless stream function $f(\eta)$ temperature $\theta(\eta)$ and concentration $\phi(\eta)$ as

$$
\begin{gathered}
\eta=y \sqrt{\frac{U_{0}}{v x}}=\frac{y}{x} \sqrt{\operatorname{Re}_{x}}, \\
\frac{u}{U_{0}}=f^{\prime}, \quad v=\frac{1}{2 x} \sqrt{\operatorname{Re}_{x}}\left(\eta f^{\prime}-f\right), \\
\theta(\eta)=\frac{T-T_{\infty}}{T_{f}-T_{\infty}}, \quad \phi(\eta)=\frac{C-C_{\infty}}{C_{f}-C_{\infty}},
\end{gathered}
$$

where prime symbol denotes differentiation with respect to $\eta$ and $\operatorname{Re}_{x}=U_{0} x / \nu$ is the local Reynolds number. These nonlinear partial differential equations are then transformed 
by similarity transformation into a system of ordinary differential equations given as

$$
\begin{gathered}
f^{\prime \prime \prime}+\frac{1}{2} f f^{\prime}+\operatorname{Gr} \theta+\operatorname{Gc} \phi=0, \\
\theta^{\prime \prime}\left[1+\frac{4}{3} R\right]+\frac{1}{2} \operatorname{Pr} f \theta^{\prime}+\operatorname{Pr} Q e^{-\eta}+\operatorname{Ec} \operatorname{Pr}\left(f^{\prime \prime}\right)^{2}=0, \\
\phi^{\prime \prime}+\frac{1}{2} \operatorname{Sc} f \phi^{\prime}-\operatorname{Kr} \operatorname{Sc} \phi=0, \\
f(0)=0, \quad f^{\prime}(0)=1, \\
\theta^{\prime}(0)=-\operatorname{Bi}[1-\theta(0)], \quad \phi(0)=1, \\
f^{\prime}(\infty)=1, \quad \theta(\infty)=0, \quad \phi(\infty)=0,
\end{gathered}
$$

where

$$
\begin{gathered}
\mathrm{Bi}=\frac{h_{f}}{k} \sqrt{\frac{\nu x}{U_{0}}}, \quad \operatorname{Pr}=\frac{\nu}{\alpha}, \\
\mathrm{Gr}=\frac{x g \beta\left(T_{f}-T_{\infty}\right)}{U_{0}^{2}}, \quad \mathrm{Gc}=\frac{x g \beta^{*}\left(C_{f}-C_{\infty}\right)}{U_{0}^{2}}, \\
\mathrm{Ra}=\frac{4 \alpha \sigma T_{\infty}^{3}}{k K}, \quad \mathrm{Q}=\frac{x^{2} \dot{q} e^{\eta}}{k \operatorname{Re}_{x}\left(T_{f}-T_{\infty}\right)}, \\
\mathrm{Ec}=\frac{U_{0}^{2}}{k\left(T_{f}-T_{\infty}\right)}, \quad \mathrm{Sc}=\frac{\nu}{D}, \quad \mathrm{Kr}=\frac{\mathrm{Kr}^{\prime} x}{U_{0}} .
\end{gathered}
$$

$\mathrm{Bi}$ is the local Biot number, $\mathrm{Pr}$ is the Prandtl number, Gr is local Grashof number, Gc is modified local Grashof number, $\mathrm{Ra}$ is the radiation parameter, $\mathrm{Q}$ is the internal heat generation parameter, Ec is the Eckert number, Sc is the Schmidt number, and $\mathrm{Kr}$ is the chemical reaction parameter.

For the momentum and energy equations to have a similarity solution, the parameters $\mathrm{Gr}, \mathrm{Gc}, \mathrm{Q}$, and $\mathrm{Bi}_{x}$ must be constants and not functions of $x$ as in (11). This condition can be met if the heat transfer coefficient $h_{f}$ is proportional to $x^{-1 / 2}$, the thermal expansion coefficient $\beta$ is proportional to $x^{-1}$, and the internal generation $\dot{q}$ is proportional to $x^{-1}$. We therefore assume

$$
h_{f}=c x^{-1 / 2}, \quad \beta=m x^{-1} q=l x^{-1} e^{-\eta},
$$

where $c, m$, and $l$ are constants. Substituting (12) into (13), we have

$$
\begin{gathered}
\mathrm{Bi}=\frac{c}{k} \sqrt{\frac{v}{U_{0}}}, \quad \mathrm{Gr}=\frac{m g\left(T_{f}-T_{\infty}\right)}{U_{0}^{2}}, \\
\mathrm{Gc}=\frac{m g\left(C_{f}-C_{\infty}\right)}{U_{0}^{2}}, \quad Q=\frac{l \nu}{k U_{0}\left(T_{f}-T_{\infty}\right)} .
\end{gathered}
$$

With $\mathrm{Bi}, \mathrm{Q}$, and $\mathrm{Gr}, \mathrm{Gc}$ is defined by (13). The solutions of (10) yield the similarity solutions. However, the solutions generated are the local similarity solutions whenever $i, Q, \mathrm{Gr}$, and Gc are defined as in (13).

The coupled nonlinear boundary value problems represented by (10) have been solved numerically using the shooting techniques with the fourth-order Runge-Kutta method. From the numerical computations, the plate surface temperature, local skin-friction coefficient, the local Nusselt number, and the local Sherwood number which are, respectively, proportional to $\theta(0), f^{\prime \prime}(0),-\theta^{\prime}(0)$, and $-\phi^{\prime}(0)$ are worked out, and their numerical values are presented in a tabular form.

\section{Results and Discussion}

To analyze the results, numerical computation has been carried out using the method described in the previous paragraph for various governing parameters, namely, thermal Grashof number Gr, modified Grashof number Gc, Prandtl number Pr, thermal radiation parameter $R$, heat generation parameter Q, Eckert number Ec, Schmidt number Sc, chemical reaction parameter $\mathrm{Kr}$, and convective parameter $\mathrm{Bi}$. In the present study the following default parameter values are adopted for computations: $\mathrm{Gr}=1.0, \mathrm{Gc}=1.0, \mathrm{Pr}=0.72$, $R=0.5, \mathrm{Q}=0.5, \mathrm{Ec}=0.5, \mathrm{Sc}=0.6, \mathrm{Kr}=0$, and $\mathrm{Bi}=$ 0.1. All graphs therefore correspond to these values unless specifically indicated on the appropriate graph.

Table 1 shows the comparison of Makinde [14] work with the present work for $\mathrm{Ec}=R=\mathrm{Sc}=\mathrm{Kr}=\mathrm{Gc}=0$, and it is noteworthy that there is a perfect agreement. Table 2, shows the values of the skin-friction coefficient, the Nusselt number, the surface temperature, and the Sherwood number in terms of $f^{\prime \prime}(0), \theta^{\prime}(0), \theta(0)$, and $\phi^{\prime}(0)$, respectively, for various values embedded flow parameters. From Table 2, it is understood that the skin friction, the rate of heat transfer, wall surface temperature at the plate surface, and the rate of mass transfer increase with an increase in local Biot number. An increase in buoyancy forces, thermal radiation, internal heat generation, Eckert number there is an increase in skinfriction, surface temperature and the Sherwood number, but decrease in the Nusselt number. An increase in the Prandtl number there is decrease in skin friction, surface temperature and the Sherwood number, but increases the Nusselt number. However, an increase in the Schmidt number and chemical reaction parameter causes a decrease in the skin friction, the Nusselt number, and surface temperature and increase in the surface mass transfer rate, that is, the Sherwood number.

3.1. Velocity Profiles. Figures $2-10$ depict the effects of various thermophysical parameters on the fluid velocity profile. It was observed that, generally, the fluid velocity increases gradually away from the plate attain its peak value within the boundary layer and the decreases to the free stream zero value satisfying the boundary conditions. From Figures 2 and 3 , we observed that the velocity boundary layer thickness increases with an increase in the values of local Grashof number (Gr) and modified local Grashof number (Gc) due to buoyancy effect. In Figure 4, the influence of Prandtl number on the fluid velocity was displayed, and it is interesting to 
TABLE 1: Computations showing comparison with Makinde [14] results for $\mathrm{Gc}=0, \mathrm{Ec}=0, R=0, \mathrm{Sc}=0$, and $K_{r}=0$.

\begin{tabular}{|c|c|c|c|c|c|c|c|c|c|}
\hline $\mathrm{Bi}$ & $\mathrm{Gr}$ & $\operatorname{Pr}$ & $Q$ & $f^{\prime \prime}(0)$ Makinde [14] & $\theta^{\prime}(0)$ Makinde [14] & $\theta(0)$ Makinde [14] & $f^{\prime \prime}(0)$ present & $\theta^{\prime}(0)$ present & $\theta(0)$ present \\
\hline 0.1 & 0.1 & 0.72 & 1.0 & -0.2000518 & 0.076578477 & 1.76578477 & -0.253226 & 0.0353022 & 1.35302 \\
\hline 1.0 & 0.1 & 0.72 & 1.0 & -0.2459676 & 0.281651449 & 1.28165144 & -0.279242 & 0.128217 & 1.12822 \\
\hline 10 & 0.1 & 0.72 & 1.0 & -0.2695171 & 0.382952717 & 1.03829527 & -0.280211 & 0.173623 & 1.01736 \\
\hline 0.1 & 0.5 & 0.72 & 1.0 & 0.4221216 & 0.048257030 & 1.48257030 & 0.250851 & 0.016076 & 1.16076 \\
\hline 0.1 & 1.0 & 0.72 & 1.0 & 0.9895493 & 0.034011263 & 1.34011263 & 0.717892 & 0.00569792 & 1.05698 \\
\hline 0.1 & 0.1 & 3.0 & 1.0 & -0.3748695 & -0.023814576 & 0.76185423 & -0.26024 & 0.100968 & 2.00969 \\
\hline 0.1 & 0.1 & 7.10 & 1.0 & -0.4138825 & -0.057164001 & 0.42835998 & -0.258586 & 0.153863 & 2.53863 \\
\hline 0.1 & 0.1 & 0.72 & 5 & 0.3741286 & 0.576670381 & 6.76670381 & 0.198617 & 0.41344 & 5.13444 \\
\hline 0.1 & 0.1 & 0.72 & 10 & 0.9010790 & 1.106605802 & 12.0660580 & 0.620946 & 0.818126 & 9.18126 \\
\hline
\end{tabular}

TABLE 2: Computation showing $f^{\prime \prime}(0), \theta^{\prime}(0), \theta(0)$, and $\phi^{\prime}(0)$ for different embedded flow parameter values.

\begin{tabular}{|c|c|c|c|c|c|c|c|c|c|c|c|c|}
\hline $\mathrm{Bi}$ & $\mathrm{Gr}$ & $\mathrm{Gc}$ & $\operatorname{Pr}$ & $R$ & Q & Ec & $\mathrm{Sc}$ & $K_{r}$ & $f^{\prime \prime}(0)$ & $\theta^{\prime}(0)$ & $\theta(0)$ & $\phi^{\prime}(0)$ \\
\hline 0.1 & 1.0 & 1.0 & 1.0 & 0.5 & 0.1 & 0.1 & 0.6 & 0.5 & 0.617935 & 0.0690068 & 0.309932 & 0.690904 \\
\hline 1.0 & 1.0 & 1.0 & 1.0 & 0.5 & 0.1 & 0.1 & 0.6 & 0.5 & 0.995463 & 0.24145 & 0.75855 & 0.705335 \\
\hline 10.0 & 1.0 & 1.0 & 1.0 & 0.5 & 0.1 & 0.1 & 0.6 & 0.5 & 1.16294 & 0.325667 & 0.967433 & 0.71137 \\
\hline 0.1 & 2.0 & 1.0 & 1.0 & 0.5 & 0.1 & 0.1 & 0.6 & 0.5 & 0.914867 & 0.0688259 & 0.311741 & 0.703017 \\
\hline 0.1 & 3.0 & 1.0 & 1.0 & 0.5 & 0.1 & 0.1 & 0.6 & 0.5 & 1.21966 & 0.0680544 & 0.319456 & 0.714747 \\
\hline 0.1 & 1.0 & 2.0 & 1.0 & 0.5 & 0.1 & 0.1 & 0.6 & 0.5 & 1.27296 & 0.067557 & 0.32443 & 0.711755 \\
\hline 0.1 & 1.0 & 3.0 & 1.0 & 0.5 & 0.1 & 0.1 & 0.6 & 0.5 & 1.8969 & 0.064555 & 0.35445 & 0.729823 \\
\hline 0.1 & 1.0 & 1.0 & 1.0 & 0.5 & 0.1 & 0.1 & 0.6 & 0.5 & 0.598557 & 0.0696409 & 0.303591 & 0.689679 \\
\hline 0.1 & 1.0 & 1.0 & 3.0 & 0.5 & 0.1 & 0.1 & 0.6 & 0.5 & 0.537444 & 0.070888 & 0.29112 & 0.685736 \\
\hline 0.1 & 1.0 & 1.0 & 1.0 & 1.0 & 0.1 & 0.1 & 0.6 & 0.5 & 0.635229 & 0.0684205 & 0.315795 & 0.691995 \\
\hline 0.1 & 1.0 & 1.0 & 1.0 & 1.5 & 0.1 & 0.1 & 0.6 & 0.5 & 0.645997 & 0.0680532 & 0.319468 & 0.692676 \\
\hline 0.1 & 1.0 & 1.0 & 1.0 & 0.5 & 0.2 & 0.1 & 0.6 & 0.5 & 0.694807 & 0.0621171 & 0.378829 & 0.694271 \\
\hline 0.1 & 1.0 & 1.0 & 1.0 & 0.5 & 0.3 & 0.1 & 0.6 & 0.5 & 0.769222 & 0.0553443 & 0.446557 & 0.697471 \\
\hline 0.1 & 1.0 & 1.0 & 1.0 & 0.5 & 0.1 & 0.2 & 0.6 & 0.5 & 0.654059 & 0.0662619 & 0.337381 & 0.692653 \\
\hline 0.1 & 1.0 & 1.0 & 1.0 & 0.5 & 0.1 & 0.3 & 0.6 & 0.5 & 0.693151 & 0.0632311 & 0.367689 & 0.694521 \\
\hline 0.1 & 1.0 & 1.0 & 1.0 & 0.5 & 0.1 & 0.1 & 0.78 & 0.5 & 0.562746 & 0.0687271 & 0.312729 & 0.786616 \\
\hline 0.1 & 1.0 & 1.0 & 1.0 & 0.5 & 0.1 & 0.1 & 1.0 & 0.5 & 0.511741 & 0.068638 & 0.311362 & 0.889928 \\
\hline 0.1 & 1.0 & 1.0 & 1.0 & 0.5 & 0.1 & 0.1 & 0.6 & 1.0 & 0.514718 & 0.0688634 & 0.311366 & 0.877011 \\
\hline 0.1 & 1.0 & 1.0 & 1.0 & 0.5 & 0.1 & 0.1 & 0.6 & 1.5 & 0.488687 & 0.0687467 & 0.312533 & 1.03195 \\
\hline
\end{tabular}

note that velocity boundary layer thickness decreases with an increase in the Prandtl number. Figure 5 depicts the influence of thermal radiation on the fluid velocity, and it is interesting to note that increases the radiation parameter thickness the velocity boundary layer thickness away from the plate surface. Figure 6 depicts the effects of local internal heat generation parameter on the fluid velocity. An increase in the exponentially decaying internal heat generation causes a further increase in the velocity boundary layer thickness. Figure 7 represents the curve of fluid velocity against spanwise co-ordinate $\eta$ for various values of Eckert number which shows that the increase in Eckert number leads to a sudden increase in the fluid velocity immediately away from the wall plate before satisfying the boundary conditions. It is interesting to note that it thickens the velocity boundary layer thickness close to the wall plate when the velocity profile attains its maximum value point. Figure 8 and Figure 9 show the variation of the boundary layer velocity with the Schmidt number and chemical reaction parameter. From this
Figures we observed a slight decrease in the fluid velocity with an increase in Schmidt number and chemical reaction parameter. Figure 10 depicts the effects of the variation of the boundary layer velocity with the intensity of local Biot number (Bi). From this it was observed that the velocity boundary layer thicknesses slightly increase with an increase in the local Biot number due to convective heat transfer the plate surface.

3.2. Temperature Profiles. Figures $11,12,13,14$, and 15 illustrate the fluid temperature profiles within the boundary layer. Generally, the fluid temperature is maximum at the plate surface and decreases exponentially to zero value far away from the plate satisfying the boundary conditions. From these figures, it is noteworthy that the thermal boundary layer thickness increases with an increase in the exponentially decaying internal heat generation, thermal radiation, Eckert number, and local Biot number and decreases with an increase in the values of Prandtl number. At high Prandtl 


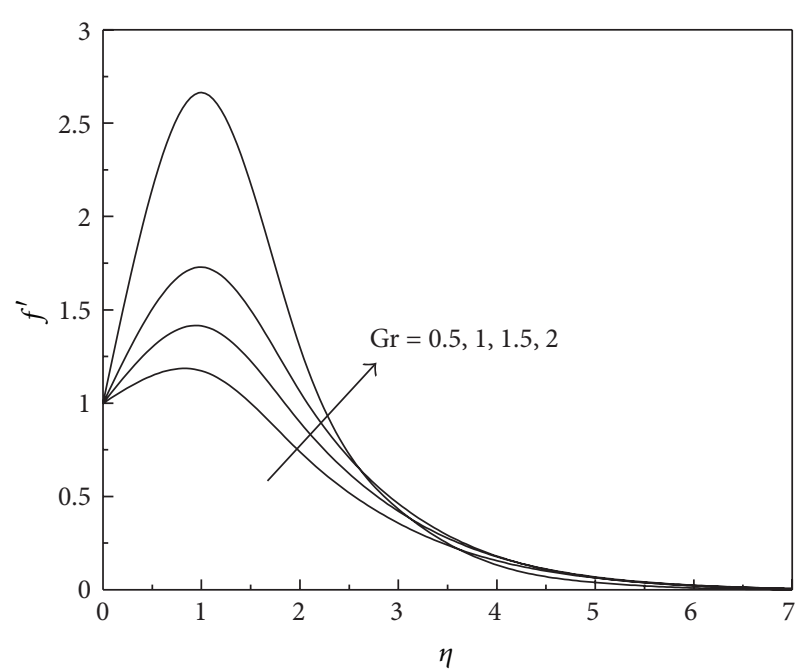

FIGURE 2: Effects of local Grashof number on velocity profile.

number has low velocity, which in turn also implies that at lower fluid velocity the species diffusion is comparatively lower and hence higher species concentration is observed at high Prandtl number.

3.3. Concentration Profiles. Figures 16 and 17 depict chemical species concentration profiles against spanwise coordinate $\eta$ for varying values of physical parameters in the boundary layer. The species concentration is highest at the plate surface and decreases to zero far away from the plate satisfying the boundary condition. From these figures, it is noteworthy that the concentration boundary layer thickness decreases with an increase in the Schmidt number and chemical reaction parameter.

Table 2 shows the values of the skin-friction coefficient, the Nusselt number, surface temperature, and the Sherwood number in terms of $f^{\prime \prime}(0), \theta^{\prime}(0), \theta(0)$, and $\phi^{\prime}(0)$, respectively, for various values of embedded flow parameters. It is understood that the skin friction, the rate of heat transfer, wall surface temperature at the plate surface, and the rate of mass transfer increase with an increase in the local Biot number. An increase in buoyancy forces (Gr, Gc), thermal radiation, internal heat generation, Eckert number there is an increase in skin-friction, surface temperature and Sherwood number and decrease in the Nusselt number. An increase in the Prandtl number there is decrease in skin-friction, surface temperature and Sherwood number, but increases the Nusselt number. However, an increase in the Schmidt number and chemical reaction parameter causes a decrease in the skin friction, the Nusselt number, and surface temperature and increases the surface mass transfer rate.

\section{Conclusions}

The similarity solution for natural convection from a moving vertical plate with internal heat generation and a convective boundary condition in the presence of thermal radiation, viscous dissipation, and chemical reaction is studied.

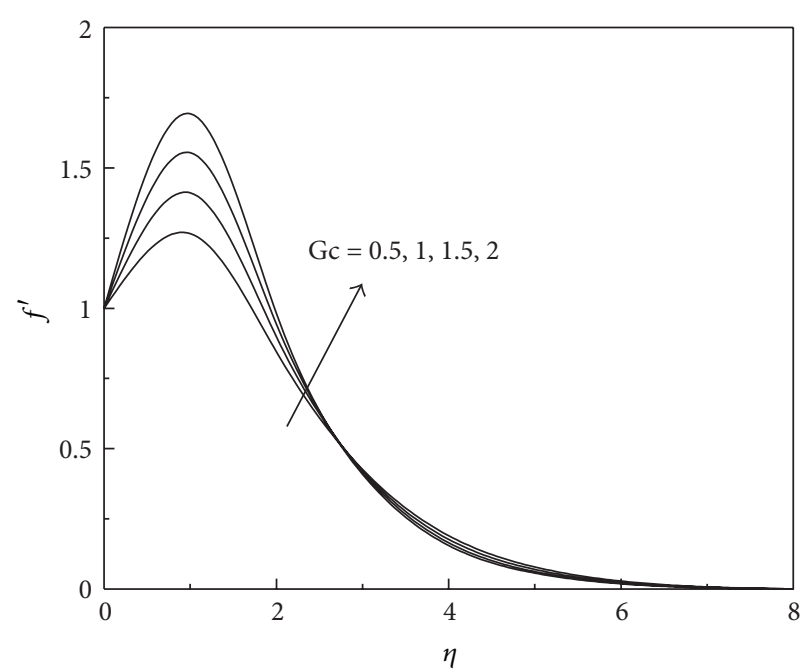

FIgURE 3: Effects of local modified Grashof number on velocity profile.

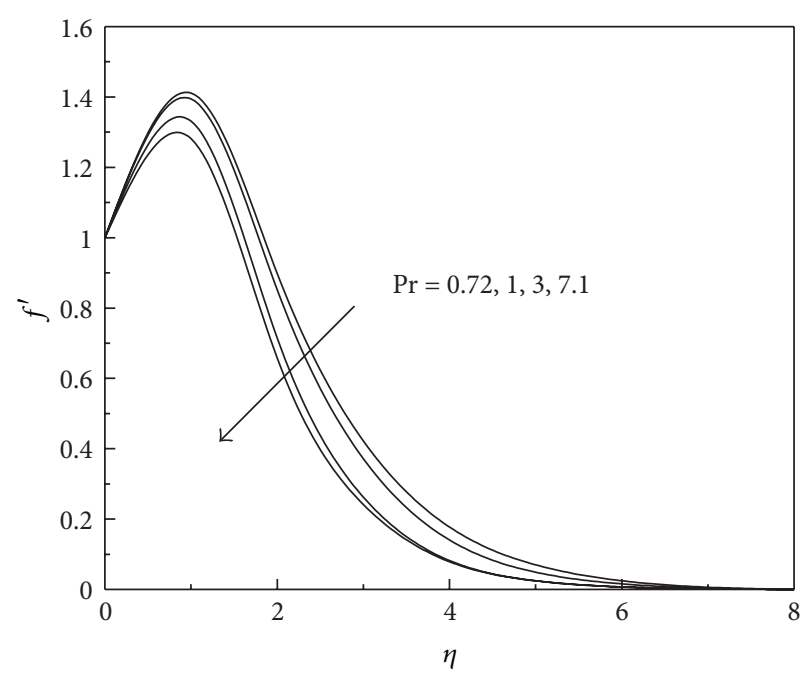

FIgURE 4: Effects of Prandtl number on velocity profile.

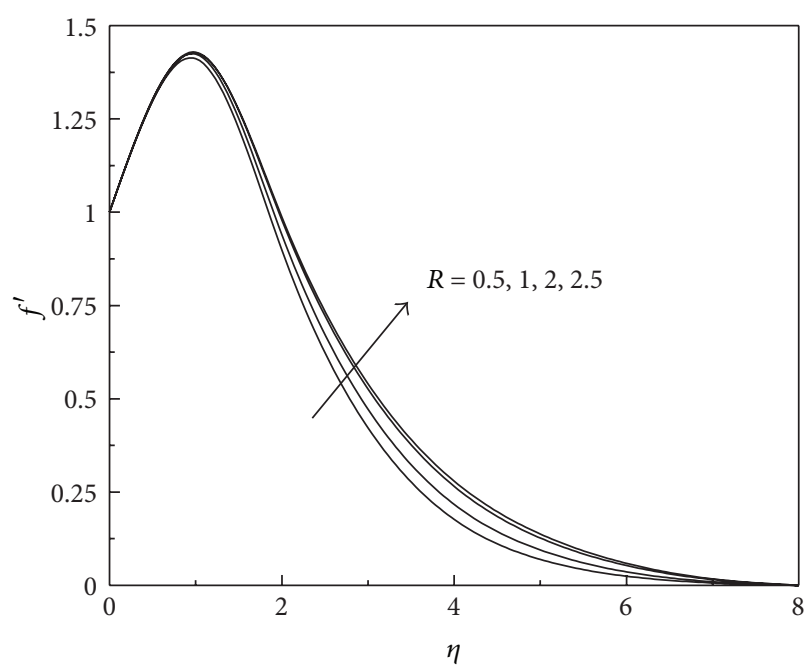

FIGURE 5: Effects of radiation parameter on velocity profile. 


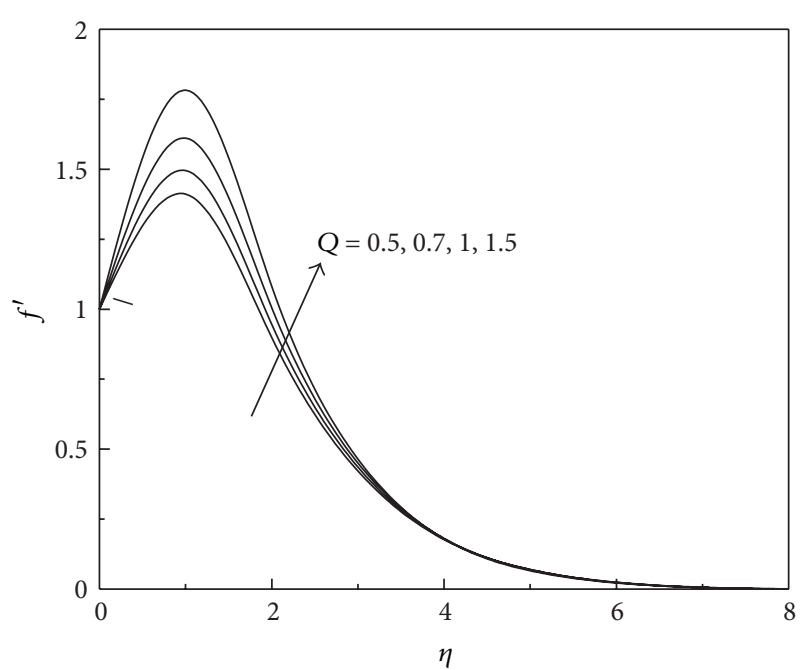

FIGURE 6: Effects of internal heat generation on velocity profile.

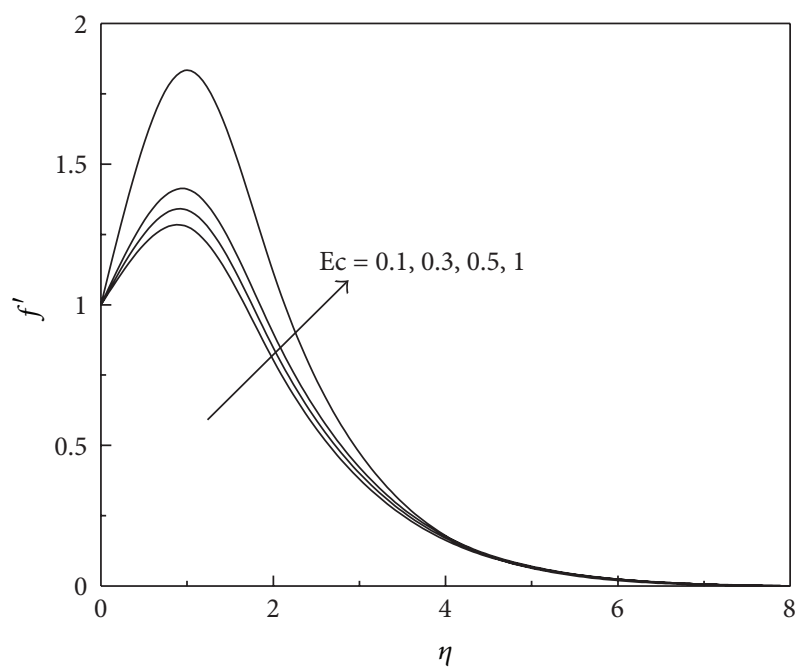

FIGURE 7: Effects of Eckert number on velocity profile.

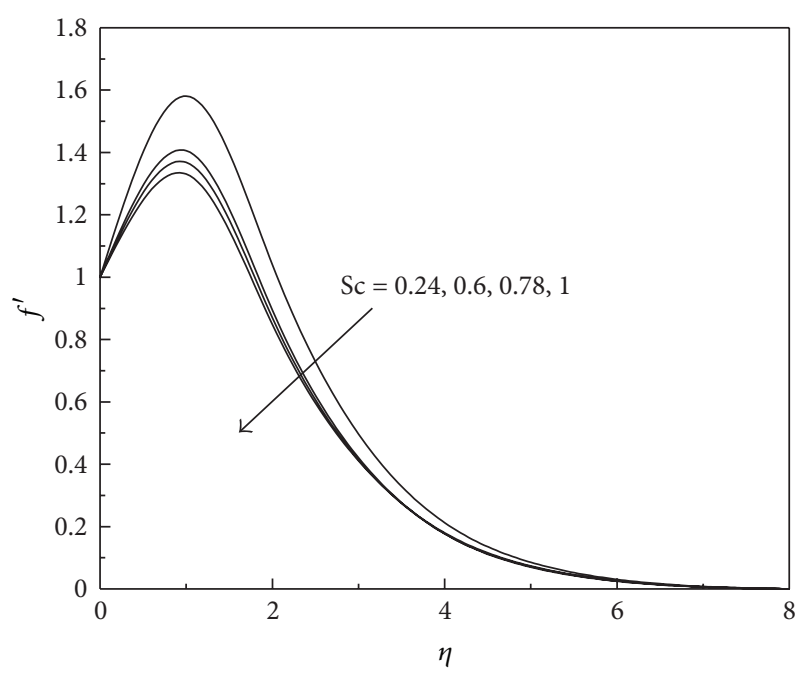

FIGURE 8: Effects of Schmidt number on velocity profile.

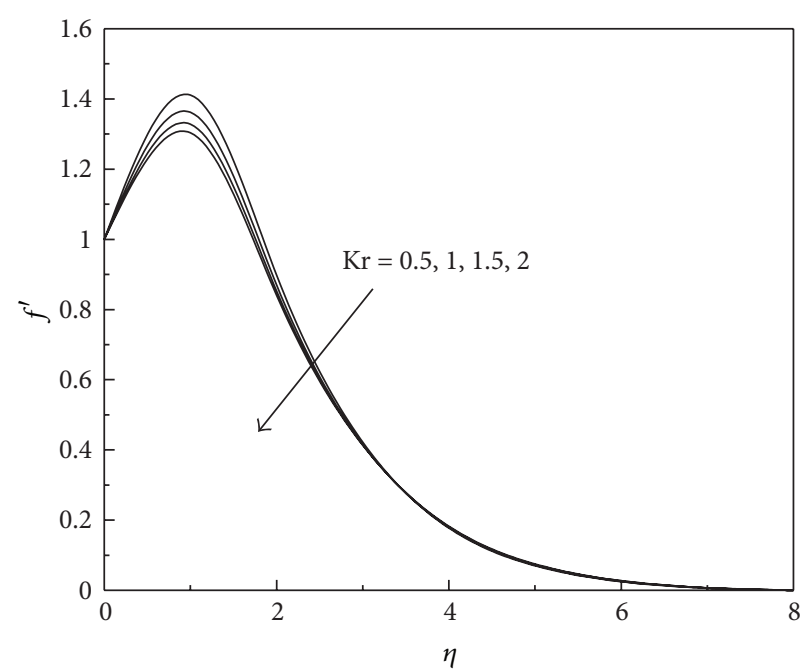

FIGURE 9: Effects of chemical reaction parameter on velocity profile.

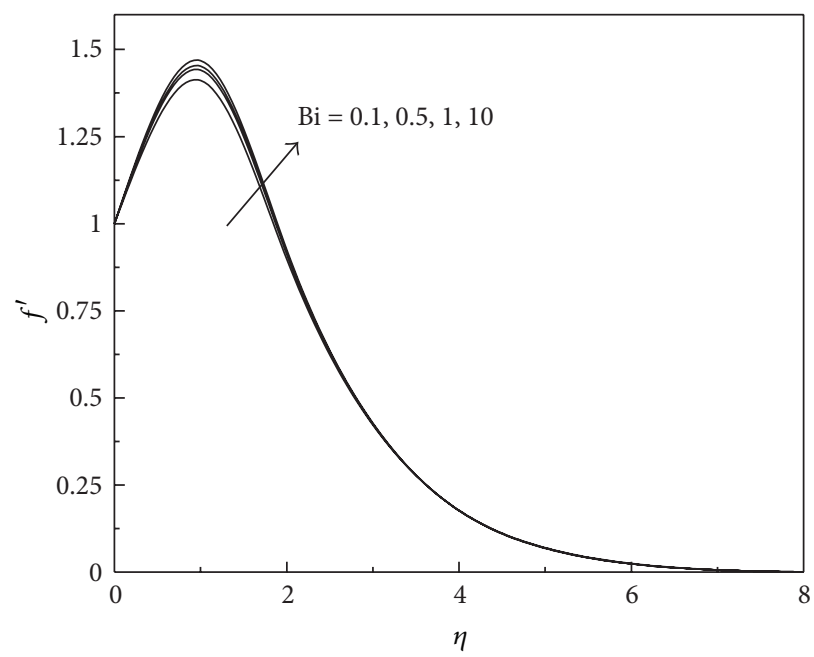

FIgURE 10: : Effects of local Biot number on velocity profile.

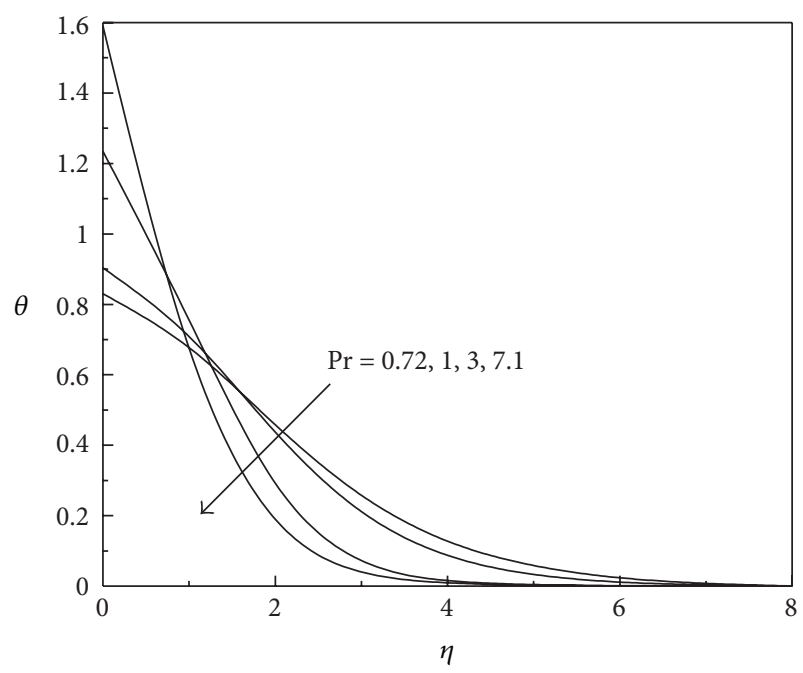

Figure 11: Effects of Prandtl number on temperature profile. 


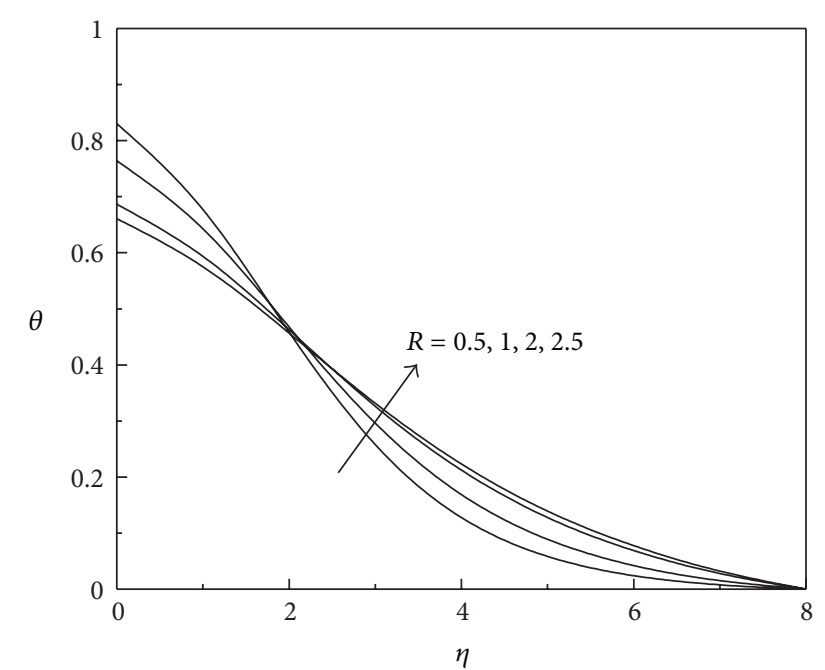

FIGURE 12: Effects of radiation parameter on temperature profile.

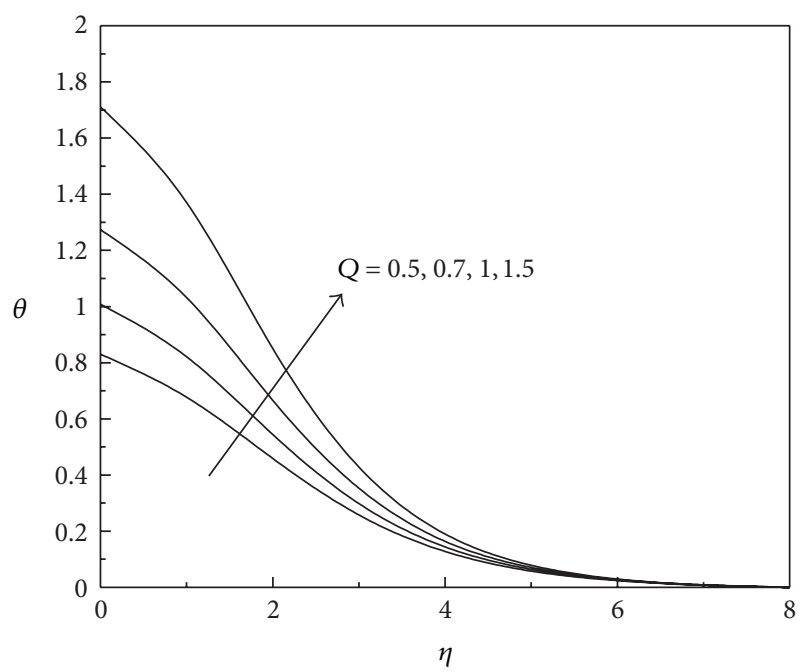

FIGURE 13: Effects of internal heat generation parameter on temperature profile.

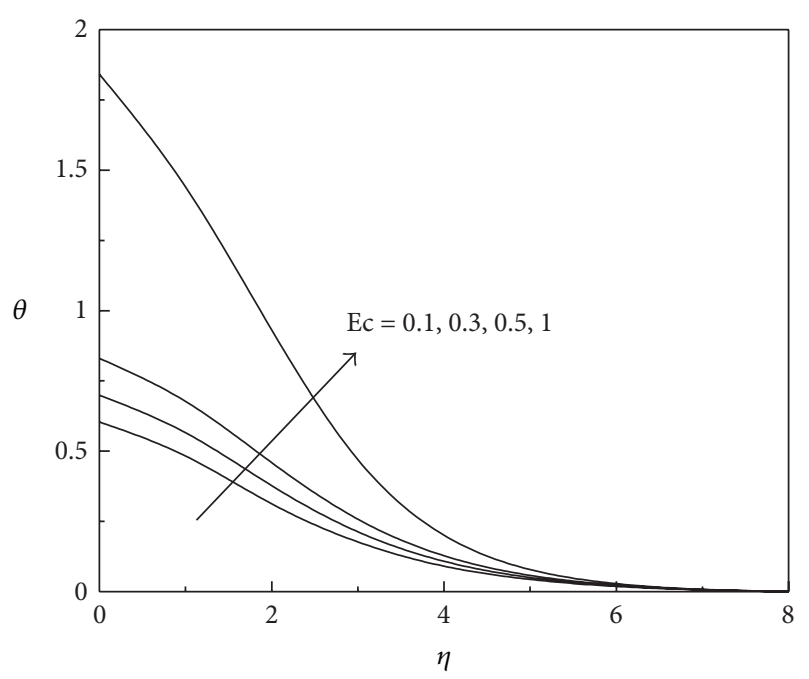

FIGURE 14: Effects of Eckert number on temperature profile.

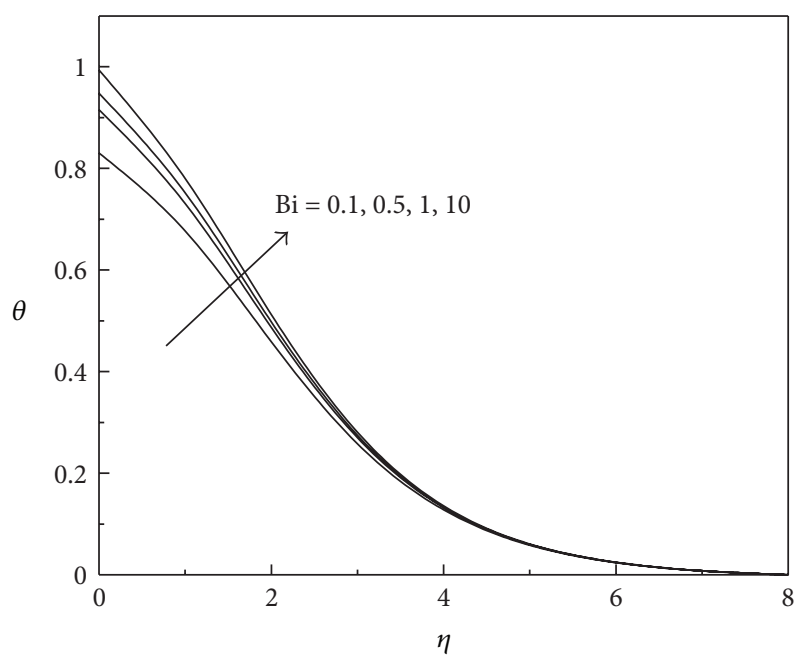

FIGURE 15: Effects of local Biot number on temperature profile.

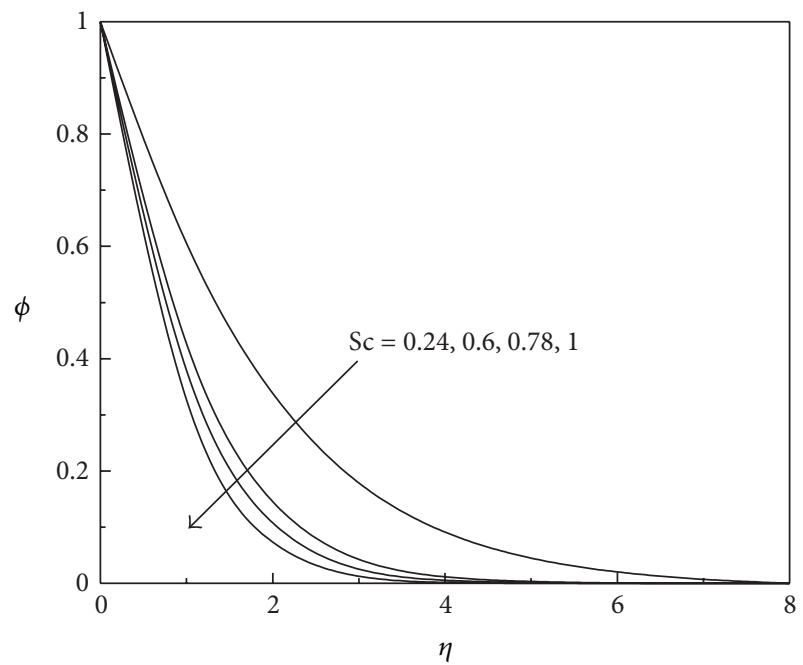

FIGURE 16: Effects of Schmidt number on concentration profile.

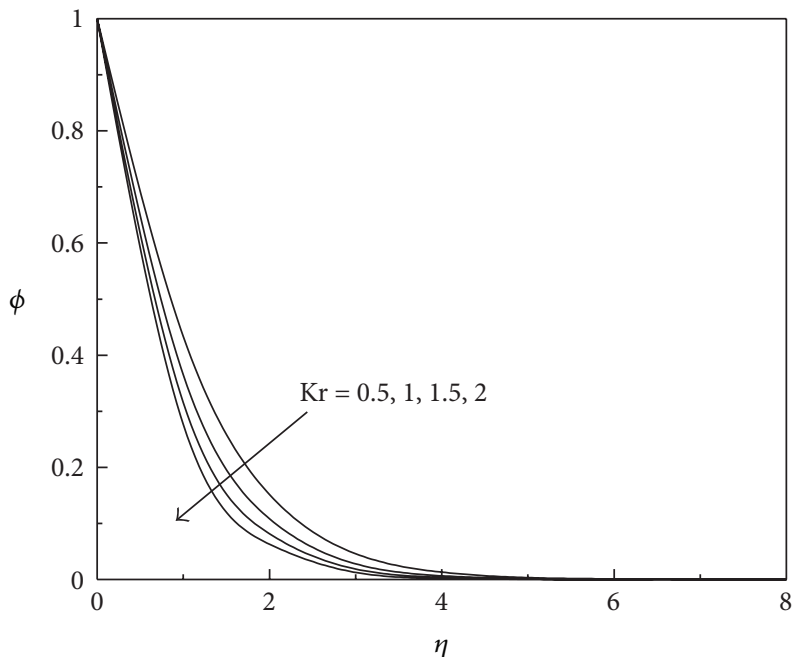

FIGURE 17: : Effects of chemical reaction parameter on concentration profile. 
A set of non-linear coupled differential equations governing the fluid velocity, temperature, and concentration is solved numerically for various material parameters. A comprehensive set of graphical results for the velocity, temperature, and concentration is presented and discussed. Our results reveal, among others, that the internal heat generation, thermal radiation, and the Eckert number prevent the flow of heat from the left surface to the right surface of the plate unless the local Grashof number is strong enough to convert away both the internally generated heat in the fluid. Generally, the fluid velocity increases gradually away from the plate, attains its peak value within the boundary layer, and decreases to the free stream zero value satisfying the boundary conditions. It is interesting to note that the fluid velocity within the boundary layer increases with increasing values of the exponentially decaying internal heat generation, thermal radiation, and the Eckert number little away from the wall plate and attains its peak before obeying the boundary conditions. The velocity and concentration both decrease with an in increase in the Schmidt number and the chemical reaction parameter.

\section{References}

[1] E. L. Cussler, Diffusion Mass Transfer in Fluid Systems, Cambridge University Press, London, UK, 1998.

[2] U. N. Das, R. Deka, and V. M. Soundalgekar, "Effects of mass transfer on flow past an impulsively started infinite vertical plate with constant heat flux and chemical reaction," Forschung im Ingenieurwesen/Engineering Research, vol. 60, no. 10, pp. 284287, 1994.

[3] S. P. Anjalidevi and R. Kandasamy, "Effects of chemical reaction, heat and mass transfer on laminar flow along a semi infinite horizontal plate," Heat and Mass Transfer, vol. 35, no. 6, pp. 465467, 1999.

[4] M. A. Seddeek, A. A. Darwish, and M. S. Abdelmeguid, "Effects of chemical reaction and variable viscosity on hydromagnetic mixed convection heat and mass transfer for Hiemenz flow through porous media with radiation," Communications in Nonlinear Science and Numerical Simulation, vol. 12, no. 2, pp. 195-213, 2007.

[5] A. M. Salem and M. Abd El-Aziz, "Effect of Hall currents and chemical reaction on hydromagnetic flow of a stretching vertical surface with internal heat generation/absorption," Applied Mathematical Modelling, vol. 32, no. 7, pp. 1236-1254, 2008.

[6] R. A. Mohamed, "Double-diffusive convection-radiation interaction on unsteady MHD flow over a vertical moving porous plate with heat generation and Soret effects," Applied Mathematical Sciences, vol. 3, no. 13-16, pp. 629-651, 2009.

[7] F. S. Ibrahim, A. M. Elaiw, and A. A. Bakr, "Effect of the chemical reaction and radiation absorption on the unsteady MHD free convection flow past a semi infinite vertical permeable moving plate with heat source and suction," Communications in Nonlinear Science and Numerical Simulation, vol. 13, no. 6, pp. 1056-1066, 2008.

[8] J. C. Crepeau and R. Clarksean, "Similarity solutions of natural convection with internal heat generation," Journal of Heat Transfer, vol. 119, no. 1, pp. 183-185, 1997.

[9] P. M. Patil and P. S. Kulkarni, "Effects of chemical reaction on free convective flow of a polar fluid through a porous medium in the presence of internal heat generation," International Journal of Thermal Sciences, vol. 47, no. 8, pp. 1043-1054, 2008.
[10] A. Mahdy, "Effect of chemical reaction and heat generation or absorption on double-diffusive convection from a vertical truncated cone in porous media with variable viscosity," International Communications in Heat and Mass Transfer, vol. 37, no. 5, pp. 548-554, 2010.

[11] A. Ishak, "Similarity solutions for flow and heat transfer over a permeable surface with convective boundary condition," Applied Mathematics and Computation, vol. 217, no. 2, pp. 837$842,2010$.

[12] A. Aziz, "A similarity solution for laminar thermal boundary layer over a flat plate with a convective surface boundary condition," Communications in Nonlinear Science and Numerical Simulation, vol. 14, no. 4, pp. 1064-1068, 2009.

[13] O. D. Makinde and P. O. Olanrewaju, "Buoyancy effects on thermal boundary layer over a vertical plate with a convective surface boundary condition," Journal of Fluids Engineering, vol. 132, no. 4, Article ID 044502, 4 pages, 2010.

[14] O. D. Makinde, "Similarity solution for natural convection from a moving vertical plate with internal heat generation and a convective boundary condition," Thermal Science, vol. 15, pp. S137-S143, 2011.

[15] P. O. Olanrewaju, J. A. Gbadeyan, T. Hayat, and A. A. Hendi, "Effects of internal heat generation, thermal radiation and buoyancy force on a boundary layer over a vertical plate with a convective surface boundary condition," South African Journal of Science, vol. 107, no. 9-10, article 476, 6 pages, 2011.

[16] O. D. Makinde and P. O. Olanrewaju, "Combined effects of internal heat generation and buoyancy force on boundary layer flow over a vertical plate with a convective surface boundary condition," The Canadian Journal of Chemical Engineering, vol. 90, no. 5, pp. 1289-1294, 2011.

[17] R. M. Sonth, S. K. Khan, M. S. Abel, and K. V. Prasad, "Heat and mass transfer in a visco-elastic fluid flow over an accelerating surface with heat source/sink and viscous dissipation," Heat and Mass Transfer, vol. 38, no. 3, pp. 213-220, 2002.

[18] C.-H. Chen, "Combined heat and mass transfer in MHD free convection from a vertical surface with Ohmic heating and viscous dissipation," International Journal of Engineering Science, vol. 42, no. 7, pp. 699-713, 2004.

[19] E. M. Abo-Eldahab and M. A. El Aziz, "Viscous dissipation and Joule heating effects on MHD-free convection from a vertical plate with power-law variation in surface temperature in the presence of Hall and ion-slip currents," Applied Mathematical Modelling, vol. 29, no. 6, pp. 579-595, 2005.

[20] D. Pal and H. Mondal, "Effects of Soret Dufour, chemical reaction and thermal radiation on MHD non-Darcy unsteady mixed convective heat and mass transfer over a stretching sheet," Communications in Nonlinear Science and Numerical Simulation, vol. 16, no. 4, pp. 1942-1958, 2011.

[21] I. J. Uwanta, "Effects of chemical reaction and radiation on heat and mass transfer past a semi-infinite vertical porous plate with constant mass flux and dissipation," European Journal of Scientific Research, vol. 87, no. 2, pp. 190-200, 2012.

[22] P. O. Olanrewaju, J. A. Gbadeyan, T. Hayat, and A. A. Hendi, "Effects of internal heat generation, thermal radiation and buoyancy force on a boundary layer over a vertical plate with a convective surface boundary condition," South African Journal of Science, vol. 107, no. 9-10, pp. 1-6, 2011.

[23] M. A. Hossain, M. A. Alim, and D. A. S. Rees, "The effect of radiation on free convection from a porous vertical plate," International Journal of Heat and Mass Transfer, vol. 42, no. 1, pp. 181-191, 1998. 
[24] A. Raptis, "Flow of a micropolar fluid past a continuously moving plate by the presence of radiation," International Journal of Heat and Mass Transfer, vol. 41, no. 18, pp. 2865-2866, 1998.

[25] A. J. Chamkha, "Hydromagnetic natural convection from an isothermal inclined surface adjacent to a thermally stratified porous medium," International Journal of Engineering Science, vol. 35, no. 10-11, pp. 975-986, 1997. 

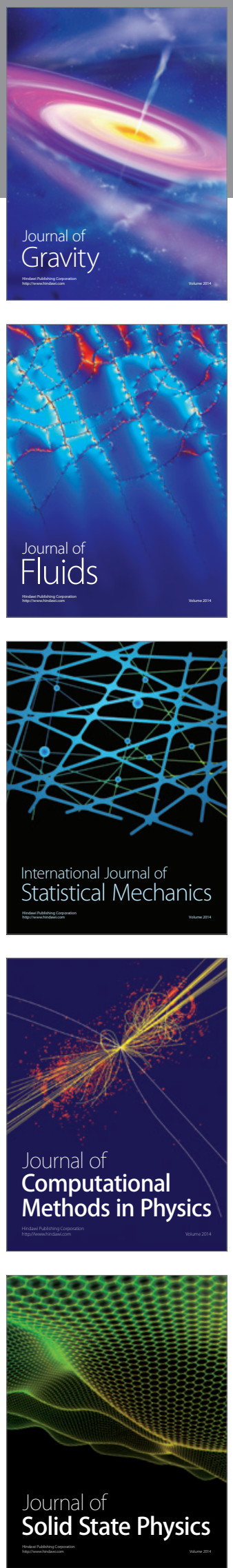

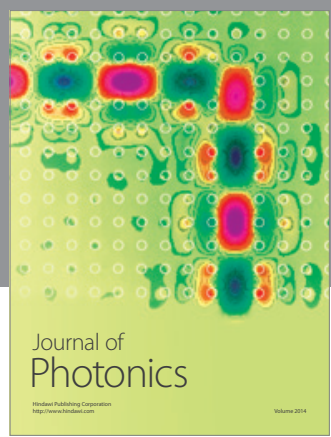

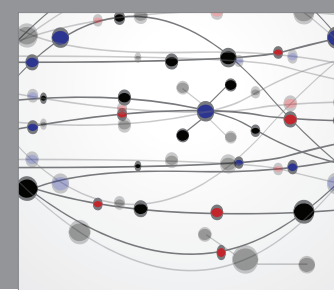

The Scientific World Journal

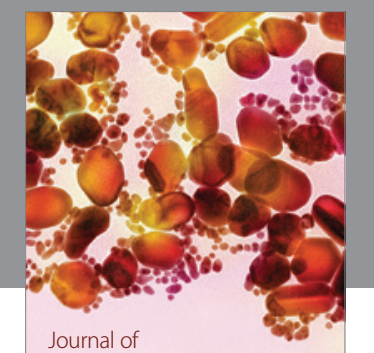

Soft Matter
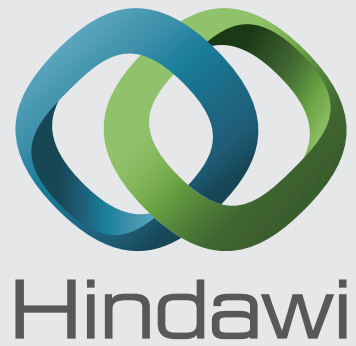

Submit your manuscripts at

http://www.hindawi.com
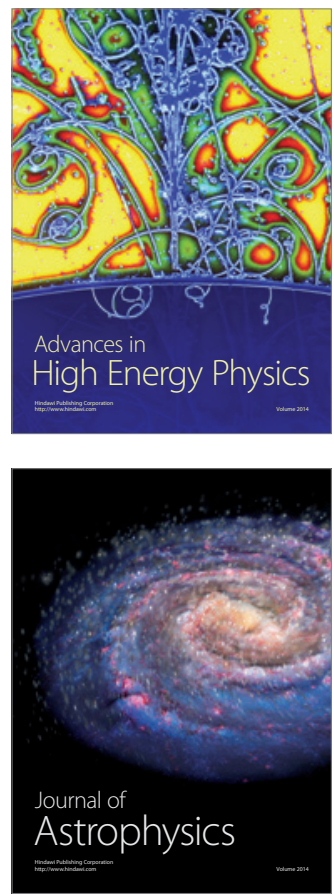
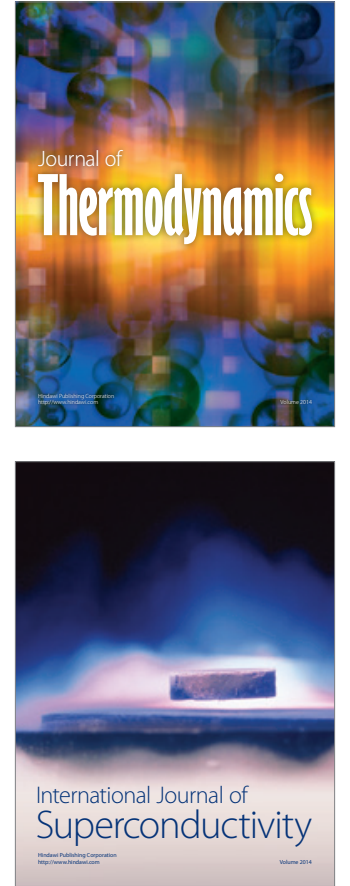
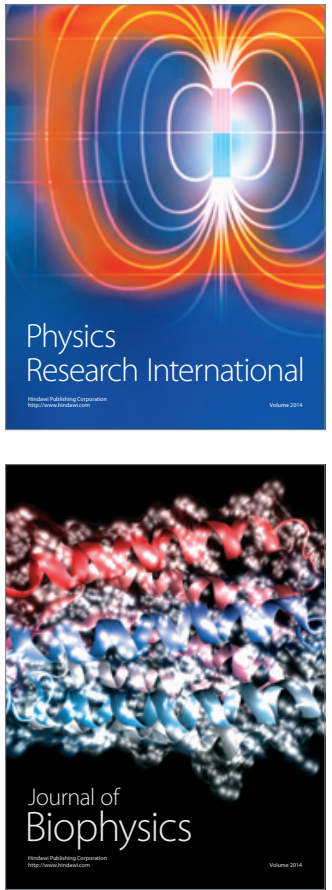
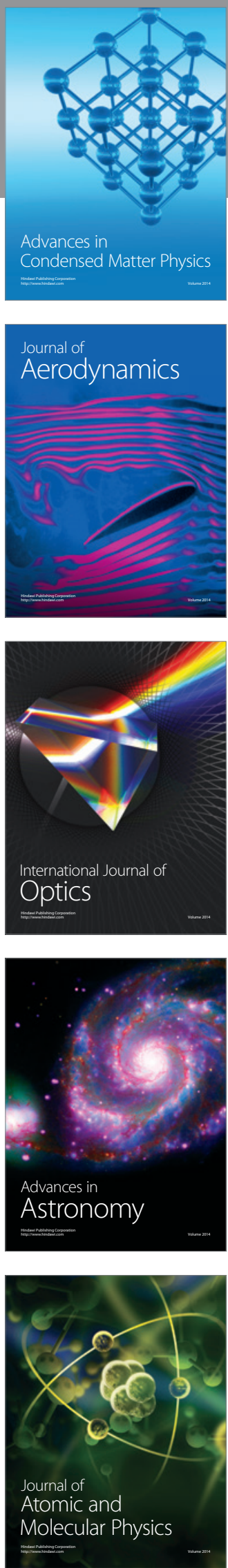